\title{
Herança de acilaçúcares em genótipos de tomateiro provenientes de cruzamento interespecífico
}

\author{
Luciano Donizete Gonçalves ${ }^{(1)}$, Wilson Roberto Maluf(2), Maria das Graças Cardoso(3), \\ Luiz Antônio Augusto Gomes ${ }^{(2)}$ e lldon Rodrigues do Nascimento ${ }^{(2)}$
}

(1)Empresa de Pesquisa Agropecuária de Minas Gerais, Fazenda Experimental Santa Rita, Caixa Postal 295, CEP 35701-970 Sete Lagoas,
MG. E-mail: ludonizete@yahoo.com.br (2)Universidade Federal de Lavras (UFLA), Dep. de Agricultura, Caixa Postal 3.037, CEP 37.200-000
Lavras, MG. E-mail: wrmaluf@ufla.br, laagomes@ufla.br, nascimento_ildon@yahoo.com.br (3)UFLA, Dep. de Química. E-mail: mcardoso@ufla.br

Resumo - O objetivo deste trabalho foi determinar a herança da produção de acilaçúcares em genótipos de tomateiro, em uma população segregante $\left(\mathrm{F}_{2}\right)$ do terceiro retrocruzamento, para Lycopersicon esculentum Mill. 'TOM-584', a partir da espécie L. pennellii 'LA-716'. A determinação do teor de acilaçúcares foi realizada com metodologia para determinação de açúcares redutores. Os dados foram utilizados para verificação da herança monogênica, sob diferentes graus de dominância (GD) presumidos, por meio do teste qui-quadrado. Para verificar a existência de efeitos aditivos e não aditivos de um gene maior e de possíveis poligenes, utilizou-se o método da máxima verossimilhança. Para os diferentes GD testados, na faixa compreendida entre - 0,7 e - 0,4 , a hipótese de herança monogênica não pôde ser descartada, o que indica a ação de alelo recessivo, com dominância incompleta na expressão de alto teor de acilaçúcares. Por meio de modelos genéticos pela função de verossimilhança, a hipótese de herança monogênica foi confirmada. Plantas de tomateiro, com boa resistência a artrópodospraga, mediada pelo aleloquímico acilaçúcar, podem ser obtidas com eficiência em populações de retrocruzamentos, a partir do cruzamento interespecífico L. esculentum x L. pennellii.

Termos para indexação: Lycopersicon esculentum, Lycopersicon pennellii, seleção, aleloquímico, resistência à praga.

\section{Inheritance of tomato leaflet acylsugar contents in genotypes derived from an interspecific cross}

\begin{abstract}
The objective of this work was to determine the inheritance of acylsugar contents in tomato genotypes, from the $\mathrm{F}_{2}$ generation of the third backcross of L. esculentum Mill. 'TOM-584', after the original cross with the wild accession L. pennellii 'LA-716'. Acylsugar contents in tomato leaflets were measured according to a methodology for reducing sugars determination. The data obtained were evaluated with chi-square tests of monogenic hypotheses of inheritance, under different presumed degrees of dominance, and also under genetic models with the maximum likelihood function, in which presence of a major gene and possible polygenes with additive and non additive effects were tested. For the different presumed degrees of dominance (DD) tested in an array between -0.7 and -0.4 , the hypotheses of monogenic inheritance could not be rejected, indicating that high acylsugar contents are controlled by a recessive allele in a locus with incomplete dominance. Genetic models tested under the maximum likelihood function also confirmed the hypothesis of monogenic inheritance. Tomato plants with adequate levels of acylsugar-mediated resistance to arthropod pests can be efficiently obtained in backcross populations, derived from the interspecific cross L. esculentum $\mathrm{x}$ L. pennellii.
\end{abstract}

Index terms: Lycopersicon esculentum, Lycopersicon pennellii, selection, allelochemicals, pest resistance.

\section{Introdução}

Algumas espécies do gênero Lycopersicon apresentam elevada resistência a artrópodos-praga e apresentam potencial para utilização em programas de melhoramento genético que visam a obtenção de cultivares comerciais resistentes. A resistência dessas espécies ocorre, principalmente, em razão da presença de subs- tâncias químicas que, na maioria dos casos, estão presentes nos tricomas glandulares, os quais podem servir também como fator morfológico de resistência (Barona et al., 1989; Eigenbrode \& Trumble, 1993; Lourenção \& Nagai, 1994; Leite et al., 1999; Maluf et al., 2001; Freitas et al., 2002; Resende et al., 2002b; Gonçalves et al., 2006). 
Os acilaçúcares são complexos formados, principalmente, por 2,3,4-tri-O-éster de glicose, que possuem ácidos graxos com 4 a 12 átomos de carbono (Burke et al., 1987). A presença desses aleloquímicos, no acesso selvagem de tomateiro Lycopersicon pennellii 'LA-716', confere resistência a um grande número de pragas, inclusive àquelas consideradas pragas-chave na cultura do tomateiro. Sua presença também foi identificada em outras espécies do gênero Lycopersicon, bem como em outros gêneros da família Solanaceae, inclusive Solanum, Nicotiana e Datura (Severson et al., 1985; King et al., 1990; Shinozaki et al., 1991). Esse grupo de fitoquímicos pode atuar de modo a impedir a oviposição e a alimentação ou, ainda, a exercer efeito deletério no desenvolvimento de determinadas fases dos artrópodos-praga (Goffreda et al., 1989; Liedl et al., 1995; Resende et al., 2002a, 2006; Baldin et al., 2005).

Vários estudos com L. pennellii 'LA-716' demonstraram alta resistência dessa espécie a artrópodos-praga de importância na cultura, como traça-do-tomateiro (Resende et al., 2006), mosca-branca (Berlinger \& Dahan, 1984; Resende, 2003; Baldin et al., 2005), ácarovermelho (Resende et al., 2002b) e ácaro-rajado (Maruyama et al., 2002). Esses resultados indicam o grande potencial de utilização dessa espécie, como fonte de resistência para a obtenção de cultivares comerciais de tomateiro, adequadas ao manejo e ao controle de pragas.

Resende (2003) trabalhou com plantas selecionadas para alto e baixo teor de acilaçúcares, na população $F_{2}$ do cruzamento L. esculentum Mill. 'TOM-584' $\mathrm{x}$ L. pennellii 'LA-716', e na população $\mathrm{F}_{2}$ do primeiro retrocruzamento para L. esculentum. Essas plantas foram submetidas a ensaios de repelência ao ácaro Tetranychus evansi, e de resistência à mosca-branca e à traça-do-tomateiro, juntamente com os genitores. Os resultados demonstraram o efeito positivo dos acilaçúcares, na repelência ao ácaro Tetranychus evansi. Nos ensaios com mosca-branca, verificou-se um menor número de ninfas para todos os genótipos com elevado teor de acilaçúcares, o que evidencia o efeito do tipo antibiose sobre o desenvolvimento desse insetopraga. Alto teor de acilaçúcares também foi associado à resistência à traça-do-tomateiro, em ensaios realizados tanto em casa de vegetação quanto no campo. Os estudos de Resende (2003) indicaram que a seleção para alto teor de acilaçúcares pode constituir-se num eficiente critério de seleção indireta, para resistência a um amplo espectro de artrópodos-praga.
Estudos da herança do teor de acilaçúcar em populações $F_{1}$ e $F_{2}$, oriundas do cruzamento entre L. esculentum e o acesso selvagem L pennellii 'LA-716', demonstraram que apenas um gene está envolvido na produção desse caráter (Resende et al., 2002 b). Esses autores estimaram o valor de 1,36 relativo ao número de genes que controlam o caráter, e determinaram um valor de grau médio de dominância (GMD) de $-0,74$, pela metodologia de Mather \& Jinks (1984). Por meio de testes de hipóteses de herança monogênica, sob diferentes GMD, observaram que essa hipótese não pôde ser descartada, na faixa de GMD compreendida entre -1,20 e -0,60. Assim, um único loco gênico parece ser responsável pelo controle genético dos teores de acilaçúcares, embora não se exclua a possibilidade de existência de genes modificadores. $\mathrm{O}$ valor de GMD encontrado, bem como a distribuição de frequiência nas populações avaliadas, indicou que um alelo recessivo com dominância incompleta, presente em 'LA-716' é responsável por alto teor do aleloquímico.

Observa-se, entretanto, que os trabalhos dos quais se obtiveram essas informações utilizaram populações oriundas diretamente do cruzamento interespecífico com o acesso selvagem $L$. pennellii. $\mathrm{O}$ uso de acessos selvagens em cruzamentos pode provocar distorções nas distribuições mendelianas (Sawant, 1958; Zamir \& Tadmor, 1986) e, desse modo, os parâmetros genéticos determinados podem apresentar inconsistência. Com isso, a utilização de genótipos que apresentem constituição genotípica essencialmente de L. esculentum poderá fornecer informações mais seguras a respeito do controle genético da característica teor de acilaçúcares. Resultados discrepantes da hipótese de herança monogênica têm sido encontrados para a herança do teor de acilaçúcares.

Mutschler et al. (1996) também trabalharam com a geração $\mathrm{F}_{2}$, de um cruzamento entre L. esculentum $\mathrm{x}$ L. pennellii 'LA-716', e indicaram duas regiões no cromossomo 2 , além de uma região em cada um dos cromossomos 3, 4 e 11, que afetavam um ou mais aspectos da produção de acilaçúcares. Blauth et al. (1998) demonstraram a associação de dez regiões genômicas associadas à produção de acilaçúcares, em genótipos oriundos do mesmo cruzamento interespecífico. Entre essas regiões, os autores destacam os cromossomos 3 , 4 e 10 e ainda relatam que o loco gênico do cromossomo 4 está associado à área foliar apresentada pela planta. Como os acilaçúcares são produzidos nas folhas, uma maior área foliar implica em maior produção do 
aleloquímico, o que explica a associação encontrada pelos autores entre a região do cromossomo 4 e a característica, que demonstra que essa região não atua diretamente na determinação da produção de acilaçúcares.

As controvérsias nos estudos realizados até o momento demonstram, portanto, que são necessários novos trabalhos que confirmem o tipo de herança envolvida, de modo a facilitar a introgressão dessa característica em L. esculentum.

O trabalho teve por objetivo determinar a herança da produção de acilaçúcares, em genótipos de tomateiro, pela quantificação desse aleloquímico em uma população segregante $\left(\mathrm{F}_{2}\right)$ do terceiro retrocruzamento para L. esculentum, a partir da espécie selvagem $L$. pennellii 'LA-716'. Uma vez que os estudos se realizaram em material com constituição genotípica essencialmente L. esculentum, eles estiveram menos sujeitos a desvios da segregação monogênica, possivelmente existentes no cruzamento interespecífico L. esculentum $\mathrm{x}$ L. pennellii.

\section{Material e Métodos}

O experimento, realizado no período de setembro a dezembro de 2003, foi conduzido em casa de vegetação, na Estação Experimental da empresa HortAgro Sementes Ltda. em Ijaci, MG, e as avaliações foram realizadas no Laboratório de Química Orgânica, no Departamento de Química, da Universidade Federal de Lavras.

As sementes dos genótipos foram distribuídas em bandejas de poliestireno expandido, com substrato comercial Plantimax e casca de arroz carbonizada, na proporção $1: 1$, transplantadas posteriormente para vasos de $500 \mathrm{~mL}$. Utilizou-se o delineamento experimental em blocos ao acaso, com 5 repetições, e um total de 500 plantas, 400 das quais eram plantas da população BPX-370G, 50 eram plantas da testemunha para alto teor de acilaçúcar (L. pennelli 'LA-716') e 50 eram plantas da testemunha para baixo teor (Lycopersicon esculentum 'TOM-584'). A população BPX-370G corresponde à geração $F_{2}$ do terceiro retrocruzamento $\left(\mathrm{RC}_{3}\right)$ para L. esculentum 'TOM-584', a partir do acesso selvagem L. pennellii 'LA-716'.

Para a obtenção da geração $\mathrm{F}_{1} \mathrm{RC}_{3}$, que deu origem à geração $\mathrm{F}_{2} \mathrm{RC}_{3}$, denominada $\mathrm{BPX}-370 \mathrm{G}$, foram utilizados genótipos da geração $\mathrm{F}_{2} \mathrm{RC}_{2}$, com alto teor de acilaçúcares, que foram retrocruzados com a linhagem comercial 'TOM-584' (com baixo teor de acilaçúcares).

A determinação do teor de acilaçúcares, nos folíolos, foi realizada de acordo com metodologia para a determinação de açúcares redutores (Resende et al., 2002b). Para isto, discos foliares foram retirados de cada planta e acondicionados em tubos de ensaio. Posteriormente, procedeu-se à extração do acilaçúcar, com a adição de diclorometano e subseqüente realização de reação colorimétrica, pelo teste de Sommogy-Nelson. As amostras foram submetidas à leitura de absorbância, em aparelho espectrofotômetro, no comprimento de onda $540 \mathrm{~nm}$. Os valores de absorbância obtidos foram diretamente proporcionais à concentração de acilaçúcares nos folíolos.

Os dados obtidos foram utilizados para a determinação do tipo de herança envolvida na expressão da característica teor de acilaçúcar, avaliados sob duas metodologias diferentes: teste de hipótese de herança monogênica (sob diferentes graus médios de dominância presumidos) e teste de modelos genéticos, pela função de verossimilhança. Para a primeira metodologia, diferentes graus de dominância (GD) presumidos (Gomes et al., 2000) foram utilizados para a verificação da hipótese de herança monogênica por meio do teste qui-quadrado. Foi determinada a distribuição de frequiência dos dados apresentados pelos genitores originais ('TOM-584' e 'LA-716') e pela população segregante BPX-370G. Para os testes dos diferentes graus médios de dominância, foi utilizado o valor de absorbância de 0,43 como ponto de truncagem (PT), abaixo do qual a maioria das plantas do genitor $\mathrm{P}_{1}$ (=TOM-584) está localizada e acima do qual está a maioria dos indivíduos do genitor $\mathrm{P}_{2}$ (=LA-716).

A hipótese de herança monogênica foi testada sob vários GD, tendo-se partido das seguintes pressuposições: a) a distribuição dos dados nos genitores $\mathrm{P}_{1}$ e $\mathrm{P}_{2}$ e na população segregante BPX-370G segue uma distribuição normal; b) o ponto de truncagem (PT) foi estabelecido como 0,43 , correspondente a um valor de absorbância acima do qual se situou a maior parte das plantas de $\mathrm{P}_{2}$, e abaixo do qual se situou a maior parte das plantas de $\mathrm{P}_{1} ; \mathrm{c}$ ) para cada uma das gerações parentais, a média populacional $\left(\overline{\mathrm{P}_{1}}\right.$ e $\left.\overline{\mathrm{P}_{2}}\right)$ foi considerada igual à respectiva média estimada, e a variância verdadeira foi considerada igual à respectiva variância estimada; d) com base nas respectivas curvas normais, foram estimadas as porcentagens esperadas de plantas em $\mathrm{P}_{1}$ e $\mathrm{P}_{2}$, com média menor ou igual ao 
ponto de truncagem (PT); e) a média da geração $\mathrm{F}_{1}$ foi admitida como: $\overline{\mathrm{F}_{1}}=\frac{\left(\overline{\mathrm{P}_{1}}+\overline{\mathrm{P}_{2}}\right)}{2}+\mathrm{GD} \cdot \frac{\left(\overline{\mathrm{P}_{2}}-\overline{\mathrm{P}_{1}}\right)}{2}$, em que GD é o grau de dominância presumido e $\overline{\mathrm{P}_{1}}$ e $\overline{\mathrm{P}_{2}}$ são as médias dos respectivos parentais. A variância verdadeira para a população $F_{1}$ foi admitida como sendo igual à respectiva variância estimada; f) sob um dado grau médio de dominância presumido, a freqüência esperada de plantas com teor de acilaçúcar $\leq \mathrm{PT}$, sob a hipótese de herança monogênica, foi calculada como sendo a média ponderada das frequiências esperadas em $\mathrm{P}_{1}, \mathrm{~F}_{1}$ e $\mathrm{P}_{2}$, com ponderações de 1:2:1, respectivamente; $\mathrm{g})$ as frequiências esperadas das plantas com média $\leq \mathrm{PT}$, obtidas para $\mathrm{P}_{1}$ (item d), $\mathrm{P}_{2}$ (item d) e BPX-370G (item f) foram multiplicadas pelo número de plantas avaliadas por geração, tendo-se obtido, assim, o número esperado de plantas de $\mathrm{P}_{1}, \mathrm{P}_{2}$ e BPX-370G com média $\leq \mathrm{PT}$, sob a hipótese de herança monogênica com o grau médio de dominância considerado; h) os números esperados de plantas em $\mathrm{P}_{1}, \mathrm{P}_{2}, \quad \mathrm{BPX}-370 \mathrm{G}$ com média $\leq \mathrm{PT}$ foram comparados aos números efetivamente obtidos, tendo-se computado o valor de qui-quadrado, com 2 graus de liberdade; i) a significância do valor de quiquadrado obtido levará à rejeição da hipótese de herança monogênica sob o grau de dominância considerado. Do contrário, a não-significância do valor de qui-quadrado obtido levará à não rejeição dessa hipótese, admitindo-se, então, a possibilidade de tratar-se de herança monogênica sob o GD considerado.

Para o teste que utilizou a função de verossimilhança, Silva (2003) propôs uma metodologia para modelar e estimar parâmetros relativos ao efeito de gene maior e poligenes, ao utilizar gerações derivadas de linhagens contrastantes, que considera o método da máxima verossimilhança. Essa metodologia foi também empregada por Menezes et al. (2005). A função da máxima verossimilhança foi constituída, tendo-se considerado uma característica que pode apresentar um gene de efeito maior, bem como variação entre indivíduos de um mesmo genótipo, em razão da ação de efeitos ambientais e ou de genes de efeitos menores.

De acordo com a metodologia proposta, são determinados 9 modelos genéticos, em que cada um deles estima diferentes parâmetros, conforme segue: modelo 1 - gene maior com efeitos aditivo e de dominância + poligenes com efeitos aditivo e de dominância; modelo 2 - gene maior com efeitos aditivo e de dominância + poligenes com efeito aditivo apenas; modelo 3 - gene maior com efeito aditivo apenas + poligenes com efeitos aditivo e de dominância; modelo $4-$ gene maior com efeito aditivo apenas + poligenes com efeito aditivo apenas; modelo 5 - poligenes com efeitos aditivo e de dominância; modelo 6 - poligenes com efeito aditivo apenas; modelo 7 - gene maior com efeitos aditivo e de dominância; modelo 8 - gene maior com efeito aditivo apenas e modelo 9 - apenas efeito do ambiente.

A partir das funções de verossimilhança, para cada modelo, foi possível compor testes de interesse, tendose considerado diferentes hipóteses. Tais testes de razão de verossimilhança foram feitos por meio da estatística LR (Likelihood ratio). Os testes foram realizados com o programa estatístico Monogen v. 0.1 (Silva, 2003). Como apenas as gerações $\mathrm{P}_{1}, \mathrm{P}_{2}$ e $\mathrm{F}_{2}(=\mathrm{BPX}-370 \mathrm{G})$ foram utilizadas, a metodologia de Silva (2003) permitiu apenas alguns testes entre modelos (Tabela 1), entre os quais, os seguintes: modelo 2 vs. modelo 4 - estimou o efeito de dominância do gene maior; modelo 2 vs. modelo 6 - estimou o efeito de um gene maior com efeitos aditivos e de dominância; modelo 2 vs. modelo 7 - estimou o efeito de poligenes com efeito aditivo, que atuaram como modificadores de um gene maior; modelo 2 vs. modelo 9 - efeito de um gene com efeito aditivo e de dominância, somado ao efeito poligênico de natureza aditiva; modelo 7 vs. modelo 8 - efeito de dominância do gene maior e modelo 7 vs. modelo 9 - efeito de um gene maior com efeitos aditivos e de dominância.

\section{Resultados e Discussão}

As distribuições de frequiências, obtidas em $\mathrm{P}_{1}, \mathrm{P}_{2} \mathrm{e}$ na população $F_{2} R_{3}$, demonstram que a herança do teor de acilaçúcar parece ser controlada por gene(s)

Tabela 1. Testes de hipóteses de modelos genéticos hierárquicos para teor de acilaçúcares.

\begin{tabular}{lccc}
\hline Modelos $^{(1)}$ & Graus de liberdade & $\chi_{\mathrm{c}}{ }^{2}$ & Probabilidade \\
\hline 2 vs. 4 & 1 & 9,1184 & 0,0025304 \\
2 vs. 6 & 2 & 9,1184 & 0,0104706 \\
2 vs. 7 & 2 & 1,2313 & 0,5402786 \\
2 vs. 8 & 3 & 24,1189 & 0,0000237 \\
2 vs. 9 & 4 & 71,6690 & 0,0000003 \\
4 vs. 6 & 1 & 0,0000 & 0,9999985 \\
4 vs. 8 & 2 & 15,0005 & 0,0005530 \\
4 vs. 9 & 3 & 62,5506 & 0,0000003 \\
6 vs. 9 & 2 & 62,5506 & 0,0000004 \\
7 vs. 8 & 1 & 22,8875 & 0,0000016 \\
7 vs. 9 & 2 & 70,4376 & 0,0000003 \\
8 vs. 9 & 1 & $(2)$ & $(2)$ \\
\hline
\end{tabular}

(1) Testes de razão de verossimilhança, feitos por meio da estatística LR, com o programa estatístico Monogen v. 0.1 (Silva, 2003). (2)Valor negativo, talvez devido a problemas de convergência. 
maior(es), no entanto, sua análise gráfica não permite facilmente concluir pela existência ou não de genes modificadores (Figura 1). Os testes de hipótese de herança monogênica, para a característica teor de acilaçúcar, foram realizados numa faixa de graus de dominância (GD) entre $-1 \mathrm{e}+1$. De acordo com as estimativas de $\chi_{c}^{2}$ para o teste de herança monogênica dessa característica, não houve significância $(\mathrm{p} \leq 0,05)$, na faixa de GD que vai de $-0,7$ a $-0,4$ (Figura 2), o que indica que a hipótese de herança monogênica não foi rejeitada. Assim, o teor de acilaçúcares parece ser controlado por apenas um gene, com dominância parcial no sentido de menor teor, uma vez que valores negativos encontrados para GD indicam a ação de alelo recessivo, com dominância incompleta, para o controle de alto teor de acilaçúcares.

$\mathrm{Na}$ determinação de modelos genéticos pela função de verossimilhança (Silva, 2003), no teste que compara o modelo 7 ao modelo 9, que testa a hipótese de um
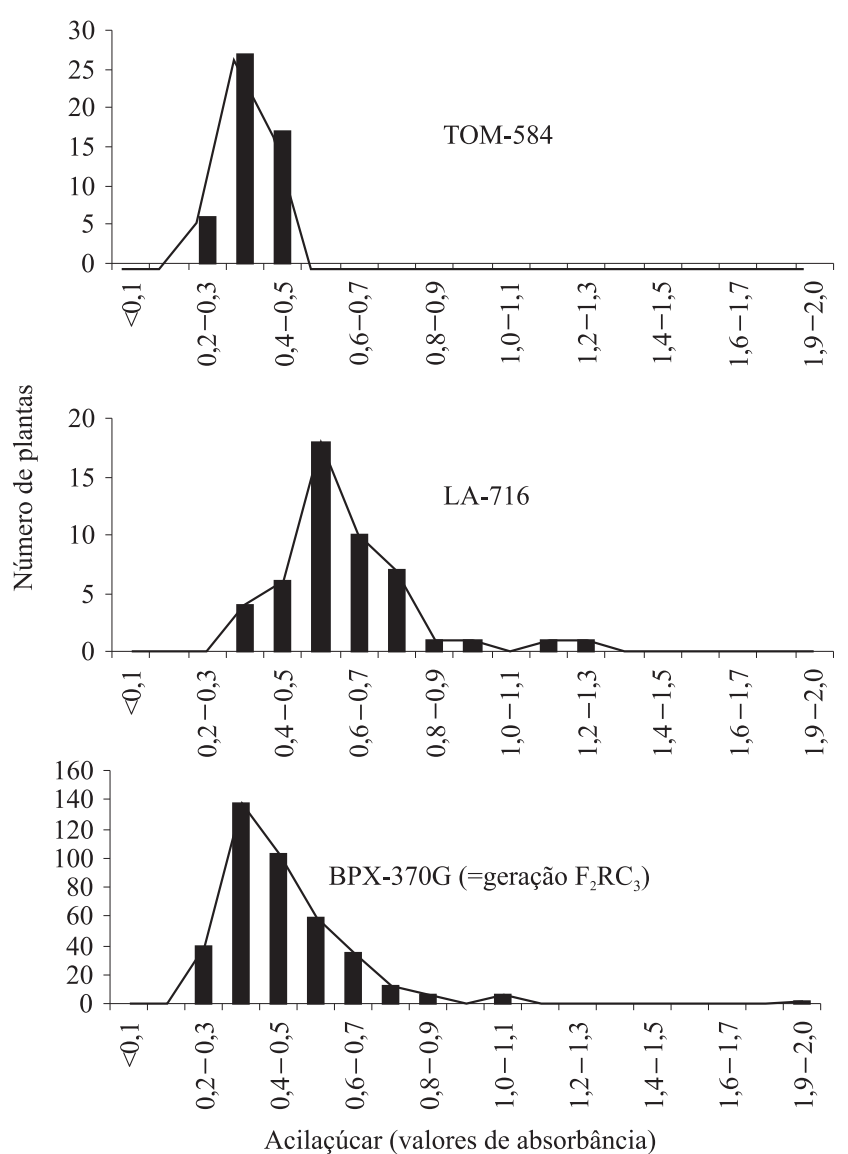

Figura 1. Distribuição de freqüências, relativa ao teor de acilaçúcares dos parentais L. esculentum 'TOM-584' e L. pennellii 'LA-716' e da geração $\mathrm{F}_{2} \mathrm{RC}_{3}$. gene maior com efeitos aditivos e de dominância, aceita-se $\mathrm{H}_{0}$, o que evidencia a herança monogênica para o caráter teor de acilaçúcar (Tabela 1). Embora a não convergência da estimativa do efeito modelo 8 vs. modelo 9 não tenha permitido estimar a significância do efeito aditivo do gene maior, o teste modelo 7 vs. modelo 9 permite concluir que há, de fato, um gene maior com efeitos aditivos e de dominância, que controla o caráter. O teste modelo 7 vs. modelo 8 permite concluir pela significância do efeito de dominância. A não-significância do teste modelo 2 vs. modelo 7 permite admitir que o caráter seja pouco ou nada influenciado por poligenes modificadores.

Ambas as metodologias utilizadas permitem aceitar a hipótese de herança monogênica do teor de acilaçúcares. $\mathrm{O}$ alto teor de acilaçúcares é controlado por um alelo recessivo com dominância incompleta, presente em L. pennellii 'LA-716' . Os dados obtidos corroboram plenamente os encontrados por Resende et al. (2002b), que obtiveram, por meio da expressão de Burton (1951), o valor de 1,36 para número de genes, o que indica tratarse de herança monogênica e que, pelo teste de herança monogênica sob diferentes GD, esta hipótese não pôde ser descartada na faixa compreendida entre $-1,20$ e $-0,60$.

Resende et al. (2002b) utilizaram as populações $F_{1} e$ $\mathrm{F}_{2}$, oriundas do cruzamento entre $L$. esculentum e o acesso selvagem L. pennellii 'LA-716', para a determinação do tipo de herança envolvida na característica. A utilização de acessos selvagens em cruzamentos interespecíficos, para a determinação dos parâmetros

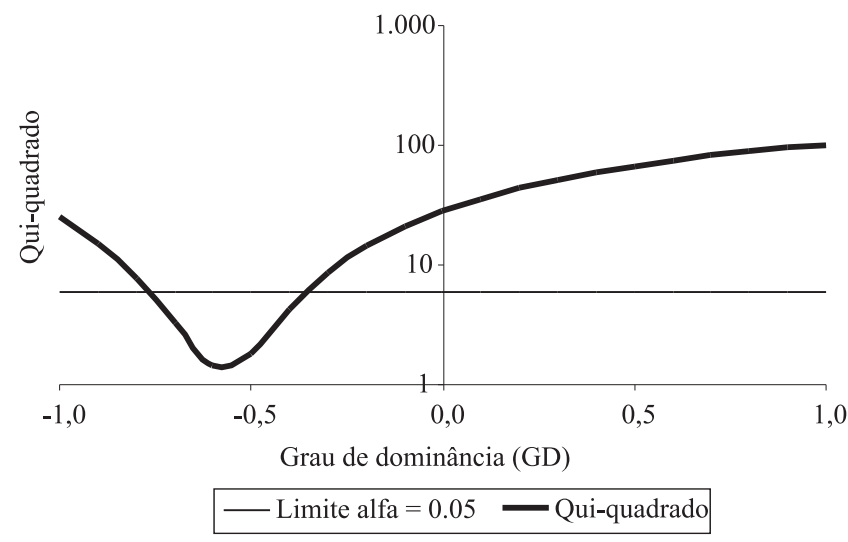

Figura 2. Testes das hipóteses de herança monogênica, sob diferentes graus de dominância, relativos ao teor de acilaçúcares em genótipos de tomateiro. 
genéticos, pode provocar distorções nas distribuições mendelianas (Sawant, 1958; Zamir \& Tadmor, 1986) e, desse modo, os parâmetros obtidos poderiam ser inconsistentes.

Neste trabalho, utilizou-se uma população do terceiro retrocruzamento, que apresenta constituição genotípica essencialmente de L. esculentum, determinando, assim, com segurança, as características genéticas envolvidas na produção de acilaçúcar. Se por um lado, os desvios da segregação mendeliana não parecem, portanto, ter ocorrido nos estudos de Resende et al. (2002b), uma vez que as conclusões foram idênticas às obtidas neste trabalho; por outro lado, os resultados aqui encontrados não necessariamente excluem os de Mutschler et al. (1996) e Blauth et al. (1998), que encontraram diferentes regiões cromossômicas, que afetam algum aspecto da produção de acilaçúcares; pois sendo os acilaçúcares um grupo bastante variado de ésteres de glicose e de sacarose, cuja porção acil varia de 4 a 12 carbonos (Burke et al., 1987), não seria surpreendente que sua síntese fosse afetada por mais de um gene, embora o efeito métrico no teor total pudesse essencialmente ser o de um loco apenas, que controlasse uma etapa crítica do processo de síntese (por exemplo, a reação de esterificação).

\section{Conclusões}

1. O caráter produção de acilaçúcar, em genótipos de tomateiro, possui herança monogênica.

2. A obtenção de plantas de tomateiro, com boa resistência a artrópodos-praga mediada pelo aleloquímico acilaçúcar, pode ser realizada com eficiência em populações de retrocruzamentos a partir do cruzamento interespecífico L. esculentum x L. pennellii.

\section{Agradecimentos}

À Coordenação de Aperfeiçoamento de Pessoal de Nível Superior (Capes), à Fundação de Amparo à Pesquisa do Estado de Minas Gerais (Fapemig), ao Conselho Nacional de Desenvolvimento Científico e Tecnológico (CNPq), à Universidade Federal de Lavras (Ufla) e à empresa HortiAgro Sementes Ltda, por viabilizarem a execução deste trabalho.

\section{Referências}

BALDIN, E.L.L.; VENDRAMIM, J.D.; LOURENÇÃO, A.L. Resistência de genótipos de tomateiro à mosca-branca Bemisia tabaci
(Gennadius) biótipo B (Hemiptera: Aleydidae). Neotropical Entomology, v.34, p.435-441, 2005.

BARONA, H.G.; PARRA, A.S.; VALLEJO, F.A.C Evaluación de especies silvestres de Lycopersicon sp., como fuente de resistencia a Scrobipalpula absoluta (Meyrick) y su intento de transferencia a Lycopersicon esculentum Mill. Acta Agronómica, v.39, p.34-45, 1989.

BERLINGER, M.J.; DAHAN, R. Resistance to the tobacco whitefly, Bemisia tabaci, in tomato and related species: a quick screening method. Bulletin IOBC/WPRS, v.1984/7, p.39-40, 1984.

BLAUTH, S.L.; CHURCHILL, G.A.; MUTSCHLER, M.A. Identification of quantitative trait loci associated with acylsugar accumulation using intraspecific populations of the wild tomato, Lycopersicon pennellii. Theoretical and Applied Genetics, v.96, p.458-467, 1998.

BURKE, B.A.; GOLDSBY, G.; MUDD, J.B. Polar epicuticular lipids of Lycopersicon pennellii. Phytochemistry, v.26, p.2567-2571, 1987.

BURTON, G.W. Quantitative inheritance in pearl millet (Pennisetum glaucum). Agronomy Journal, v.43, p.409-417, 1951.

EIGENBRODE, S.D.; TRUMBLE, J.T. Antibiosis to beet armyworm (Spodoptera exigua) in Lycopersicon accessions. HortScience, v.28, p.932-934, 1993.

FREITAS, J.A.; MALUF, W.R.; CARDOSO, M. das G.; GOMES, L.A.A.; BEARZOTTI, E. Inheritance of foliar zingiberene contents and their relationship to trichome densities and whitefly resistance in tomatoes. Euphytica, v.127, p.275-287, 2002.

GOFFREDA, J.C.; MUTSCHLER, M.A.; AVÉ, D.A.; TINGEY, W.M.; STEFFENS, J.C. Aphid deterrence by glucose esters in glandular trichome exudate of the wild tomato, Lycopersicon pennellii. Journal of Chemical Ecology, v.15, p.2135-3147, 1989.

GOMES, L.A.A.; MALUF, W.R.; CAMPOS, V.P. Inheritance of the resistant reaction of the lettuce cultivar 'Grand Rapids' to the southern root-knot nematode Meloidogyne incognita (Kofoid \& White) Chitwood. Euphytica, v.114, p.37-46, 2000.

GONÇALVES, L.D.; MALUF, W.R.; CARDOSO, M. das G.; RESENDE, J.T.V. de; CASTRO, E.M. de; SANTOS, N.M.; NASCIMENTO, I.R.; FARIA, M.F. Relação entre zingibereno, tricomas foliares e repelência de tomateiros a Tetranychus evansi. Pesquisa Agropecuária Brasileira, v.41, p.267-273, 2006.

KING, R.R.; CALHOUN, L.A.; SINGH, R.P.; BOUCHER, A. Sucrose esters associated with glandular trichomes of wild Lycopersicon species. Phytochemistry, v.29, p.2115-2118, 1990.

LEITE, G.L.D.; PICANÇO, M.; AZEVEDO, A.A.; GONRING, A.H.R. Efeito de tricomas, aleloquímicos e nutrientes na resistência de Lycopersicon hirsutum à traça-do-tomateiro. Pesquisa Agropecuária Brasileira, v.34, p.2059-2064, 1999.

LIEDL, B.E.; LAWSON, D.M.; WHITE, K.K.; SHAPIRO, J.A.; COHEN, D.E.; CARSON, W.G.; TRUMBLE, J.T.; MUTSCHLER, M.A. Acylsugars of wild tomato Lycopersicon pennellii alters settling and reduces oviposition of Bemisia argentifolii (Homoptera: Aleyrodidae). Journal of Economic Entomology, v.88, p.742-748, 1995. 
LOURENÇÃO, A.L.; NAGAI, H. Surtos populacionais de Bemisia tabaci no Estado de São Paulo. Bragantia, v.53, p.53-59, 1994.

MALUF, W.R.; CAMPOS, G.A.; CARDOSO, M.G. Relationships between trichome types and spider mite (Tetranychus evansi) repellence in tomatoes with respect to foliar zingiberene contents. Euphytica, v.121, p.73-80, 2001.

MARUYAMA, W.I.; TOSCANO, L.C.; BOIÇA JÚNIOR, A.L.; BARBOSA, J.C. Resistência de genótipos de tomateiro ao ácarorajado. Horticultura Brasileira, v.20, p.480-484, 2002.

MATHER, K.; JINKS, J.L. Introdução à genética biométrica. Ribeirão Preto: Sociedade Brasileira de Genética, 1984. 242p.

MENEZES, C.B.; MALUF, W.R.; AZEVEDO, S.M.; FARIA, M.V.; NASCIMENTO, I.R.; NOGUEIRA, D.W.; GOMES, L.A.; BEARZOTI, E. Inheritance of parthenocarpy in summer squash (Cucurbita pepo L.). Genetics and Molecular Research, v.4, p.3946, 2005.

MUTSCHLER, M.A.; DOERGE, R.W.; LIU, S.C.; KUAI, J.P.; LIEDL, B.E.; SHAPIRO, J.A. QTL analysis of pest resistance in the wild tomato Lycopersicon pennellii?: QTLs controlling acylsugar level and composition. Theoretical and Aplied Genetics, v.92, p.709-718, 1996.

RESENDE, J.T.V. de. Resistência a artrópodos-pragas, mediada por acilaçúcares em tomateiros obtidos do cruzamento interespecífico de Lycopersicon esculentum Mill. 'TOM-584' $x$ L. pennellii 'LA-716'. 2003. 91p. Tese (Doutorado) - Universidade Federal de Lavras, Lavras. Disponível em: <http:// www.posgrad.ufla.br/ASP/Teses/pesquisa.asp $>$. Acesso em: 15 fev. 2007.

RESENDE, J.T.V. de; CARDOSO, M. das G.; MALUF, W.R.; SANTOS, C.D. dos; GONÇALVES, L.D.; RESENDE, L.V.; NAVES,
F.O. Método colorimétrico para quantificação de acilaçúcares em genótipos de tomateiro. Ciência e Agrotecnologia, v.26, p.12041208, 2002a.

RESENDE, J.T.V. de; MALUF, W.R.; CARDOSO, M. das G.; NELSON, D.L.; FARIA, M.V. Inheritance of acylsugar contents in tomatoes derived from an interspecific cross with the wild tomato Lycopersicon pennellii and their effect on spider mite repellence. Genetics and Molecular Research, v.1, p.106-116, 2002b.

RESENDE, J.T.V. de; MALUF, W.R.; FARIA, M.V.; PFANN, A.Z.; NASCIMENTO, I.R. do. Acylsugars in tomato leaflets confer resistance to the South American tomato pinworm, Tuta absoluta Meyr. Scientia Agricola, v.63, p.20-25, 2006.

SAWANT, A.C. Cytogenetics of interspecific hybrids, Lycopersicon esculentum Mill. X L. hirsutum Humb. and Bonpl. Genetics, v.43, p.502-514, 1958.

SEVERSON, R.F.; ARRENDALE, R.F.; CHORTYK, O.T.; GREEN, C.R.; THOME, F.A.; STEWART, J.L.; JOHNSON, A.W. Isolation and characterization of the sucrose esters of the cuticular waxes of green tobacco leaf. Journal of Agricultural and Food Chemistry, v.33, p.870-875, 1985.

SHINOZAKI, Y.; MATSUZAKI, T.; SUHARA, S.; TOBITA, T.; SHIGEMATSU, H.; KOIWAI, A. New types of glycolipids from the surface lipids of Nicotiana umbratica. Agricultural and Biological Chemistry, v.55, p.751-756, 1991.

SILVA, W.P. Estimadores de máxima verossimilhança em misturas de densidades normais: uma aplicação em genética. 2003. 60p. Dissertação (Mestrado) - Universidade Federal de Lavras, Lavras. Disponível em: <http://www.posgrad.ufla.br/ASP/Teses/ pesquisa.asp>. Acesso em: 15 fev. 2007.

Recebido em 16 de outubro de 2006 e aprovado em 11 de abril de 2007 